\title{
Cytoarchitectural and kinetic features in the histological evaluation of follicular thyroid neoplasms
}

\author{
S Arif, J Patel, A Blanes ${ }^{1} \&$ S J Diaz-Cano ${ }^{1,2}$ \\ Departments of Pathology, Barts and The London Hospital, London, UK, ${ }^{1}$ University of Malaga School of Medicine, Malaga, \\ Spain, ${ }^{2}$ Department of Histopathology, King's College London School of Medicine, London, UK
}

Date of submission 31 May 2006

Accepted for publication 17 July 2006

Arif S, Patel J, Blanes A \& Diaz-Cano S J

(2007) Histopathology 50, 750-763

\section{Cytoarchitectural and kinetic features in the histological evaluation of follicular thyroid neoplasms}

Aims: The diagnosis of follicular thyroid carcinomas is mainly based on capsular and vascular invasion. The aim of this study was to determine the diagnostic relevance of nuclear features, inflammation and stromal changes.

Methods and results: Anisokaryosis, chromatin pattern, nucleolus, nuclear pleomorphism, nuclear/cytoplasmic ratio, necrosis, stromal changes and tumour interstitial lymphocytes (TIL) were analysed in adenomatous hyperplastic nodules (39), adenomas (43) and carcinomas (28 minimally invasive, 48 widely invasive and 27 anaplastic). Ki67 immunostaining, in situ end labelling (ISEL) for apoptosis and the Ki67/ISEL index were analysed by topographical compartments. Variables were compared by histological diagnosis using Fisher's exact test, analysis of variance and Student's $t$-tests and considered significant if $P<0.05$. TIL were absent in $96 \%$ of neoplasms and $54 \%$ of adenomatous hyperplastic nodules. Conspicuous nucleoli, increased nuclear-cytoplasmic ratio and coexistent apoptosismyxoid changes distinguished minimally invasive carcinomas from adenomas. The most specific variables of high-grade carcinoma were vasculonecrotic patterns, nuclear hyperchromatism and pleomorphism. A kinetic advantage predominated in the internal compartments of benign lesions and in the peripheral compartments of malignant lesions.

Conclusions: Follicular carcinomas show up-regulation of proliferation markers and the distinctive topographical kinetic profiles provide a basis for the distinction between benign and malignant and an explanation for the circumscription and encapsulation of benign lesions.

Keywords: anaplastic carcinoma, follicular adenoma, follicular carcinoma, growth patterns, inflammation, nuclear features, thyroid

Abbreviations: ATC, anaplastic thyroid carcinoma; FTA, follicular thyroid adenoma; FTC, follicular thyroid carcinoma; FTHN, follicular thyroid hyperplastic nodule; IC, internal compartment; ISEL, in situ end labelling; N/C, nuclear-cytoplasmic; PC, peripheral compartment; TIL, tumour interstitial lymphocytes

\section{Introduction}

One recurring question in endocrine pathology is how to differentiate hyperplasia from neoplasia. The

Address for correspondence: Salvador J Diaz-Cano MD, PhD, FRCPath, King's College Hospital, Department of Histopathology, Denmark Hill, London SE5 9RS, UK.

e-mail: salvador.diaz-cano@kcl.ac.uk increase in cell number in hyperplasia is controlled by a specific stimulus (such as over-secretion of trophic hormone), the growth rate being positively correlated with the intensity of the stimulus, while spontaneous proliferation characterizes benign neoplasms. Often subtle morphological criteria differentiate benign from malignant neoplasms. ${ }^{1}$

The diagnosis of follicular carcinoma is based purely upon architectural features: full-thickness capsular 
invasion and/or vascular invasion. It has been shown that both cancer over- and underdiagnosis are frequent errors; one reason for this may be inappropriate application of these diagnostic criteria. ${ }^{2,3}$ Their application is based on personal experience, which has the potential to lead to disagreement between pathologists, in particular in the interpretation of microfollicles intimately related to capillaries within the tumour capsule. Reliable morphological criteria to allow the distinction between hyperplastic and neoplastic lesions are lacking. To reduce this problem in controversial cases, it would be necessary to provide more explicit and categorized diagnostic criteria, complemented by cell kinetic features to support any prognostically relevant classification of thyroid carcinoma. ${ }^{4}$

Tumours can be divided into two topographical compartments (superficial/deep in luminal organs, equivalent to internal/peripheral in solid organs, Figure 1) with different cell kinetic and genetic profiles, ${ }^{5-7}$ but such an approach has not been applied to follicular thyroid lesions. Superficial/internal compartments are predominantly proliferative with a lower incidence of genetic abnormalities, while in deep/peripheral compartments invasion predominates and cells accumulate more genetic alterations. In general, proliferation and active infiltration should not be expected to occur simultaneously in the same topographical compartment, which may, in part, explain capsule development in neoplasms of solid organs.

This study aimed to analyse histological features critically to develop a systematic diagnostic approach to follicular thyroid lesions and to characterize their cellular and kinetic features by topographical compartments.

\section{Materials and methods}

CASE SELECTION AND SAMPLING

All surgical resection specimens were routinely fixed and processed for histological diagnosis, sampling either the whole capsule (encapsulated neoplasms) or a minimum of 12 blocks. Consecutive follicular thyroid lesions were selected and classified using standard criteria, ${ }^{3,8}$ including adenomatous hyperplastic nodules [follicular thyroid hyperplastic nodules (FTHN), 39], adenomas [follicular thyroid adenomas (FTA), 43], carcinomas [follicular thyroid carcinomas (FTC), 76] [28 minimally invasive (MI) and 48 widely invasive (WI)] and anaplastic carcinomas [anaplastic thyroid carcinoma (ATC), 27]. FTHN and ATC were included as benign and malignant controls for the histological and kinetic analyses. Additionally, none of the cases showed any histological evidence of papillary carcinoma and were negative for RET-PTC fusion genes (1-3) and B-RAF mutations (V600).

The morphological definition of FTHN took into account nodule size, pattern of distribution and architectural pattern. ${ }^{9,10}$ The nodules were not encapsulated, compressed the adjacent thyroid and revealed variably sized follicles, along with occasional clusters of follicular cells. Cellular hypertrophy and nuclear pleomorphism may be seen in some nodules.

\section{HISTOLOGICAL EVALUATION}

Three independent observers systematically reviewed all histological slides. In case of disagreement, the
Figure 1. Topographical compartments in neoplasms from luminal and solid organs: superficial/deep compartments in luminal organs should be equivalent to internal/peripheral compartments in solid organs,

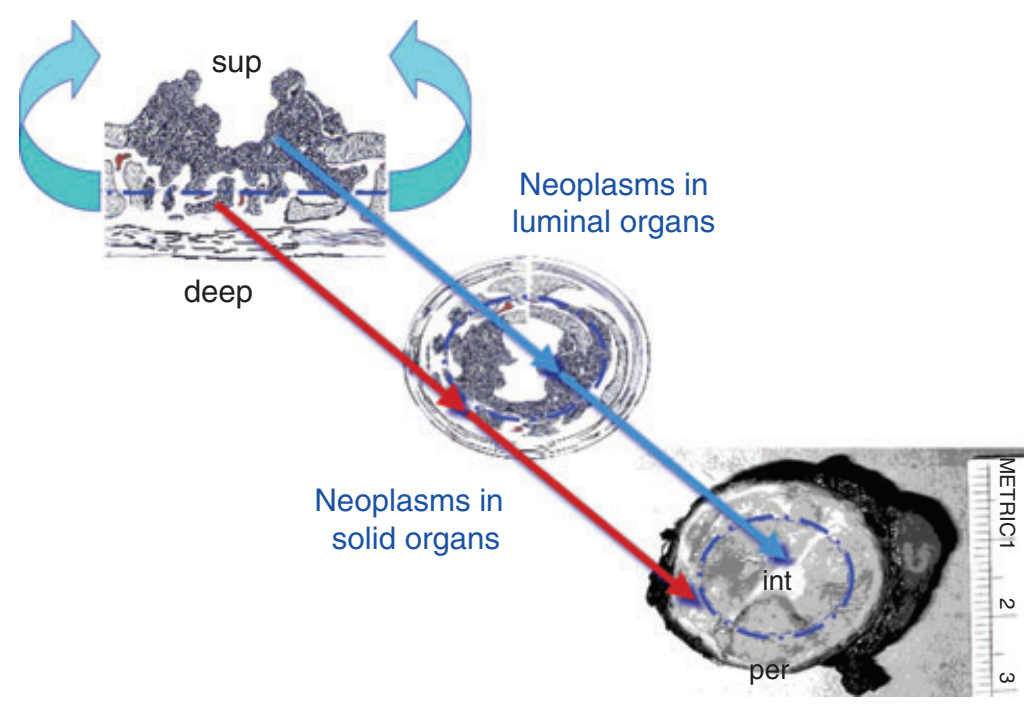



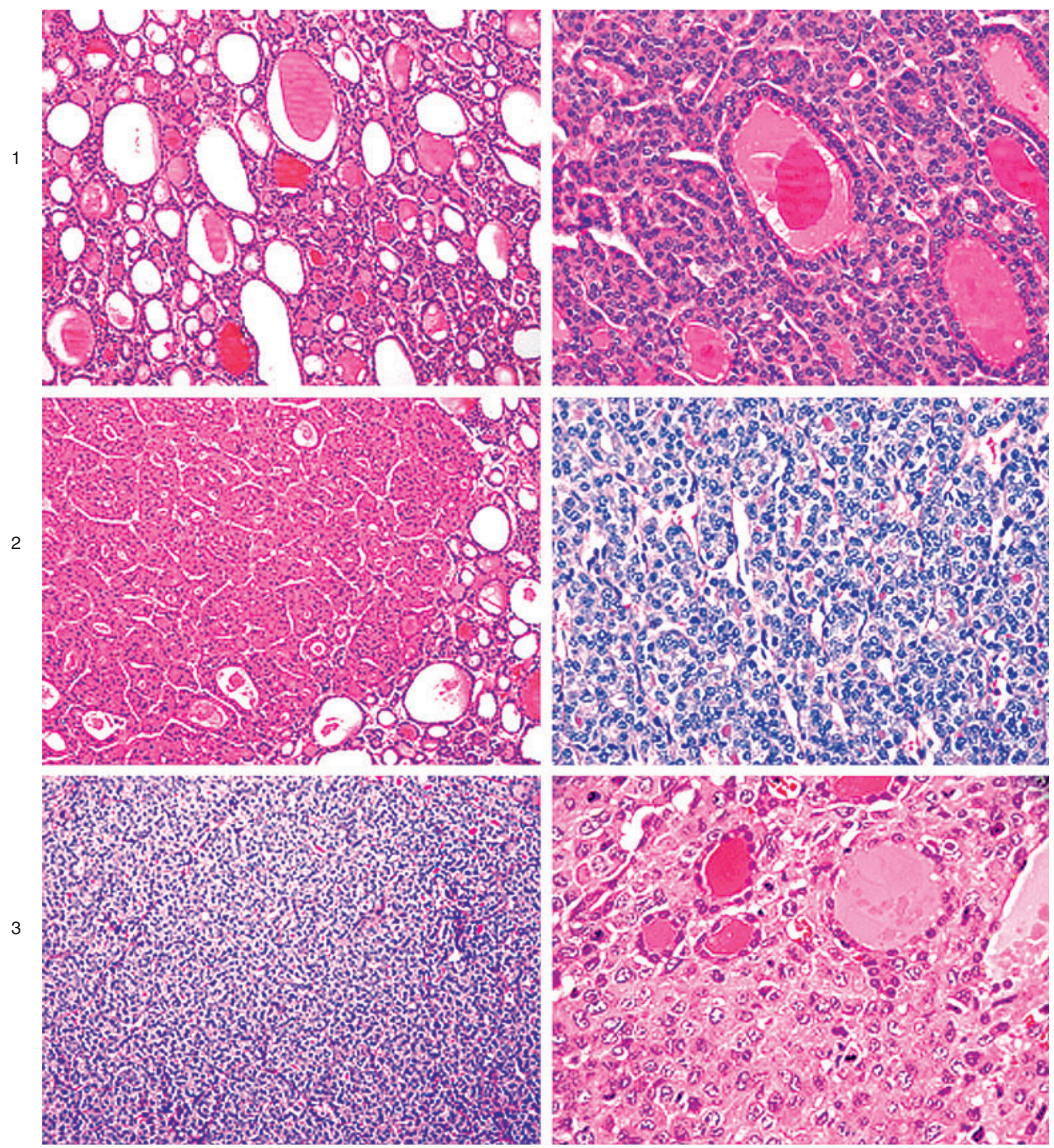

Figure 2. Architectural patterns in follicular thyroid neoplasms. The two predominant patterns were independently scored, considering macro-/ microfollicular (follicles of variable size, pattern 1), trabecular-nested (variably thick trabeculae or small solid nests, pattern 2), solid-insular (cell sheets with no defined structure or endothelialized cell groups, pattern 3) and solid-pleomorphic/vasculo-necrotic (solid plus pleomorphic cells or necrosis of tumour cells and blood vessels, pattern 4). A global score from 2 to 8 was then obtained for each neoplasm. Haematoxylin and eosin.

lesions were discussed and a final consensus categorization achieved. Reproducibility data were not recorded. The histological features included:
1 Pattern of the adjacent gland, considered as atrophic (architectural disarray in a small gland), hyperplastic (opposite features), or normal. 

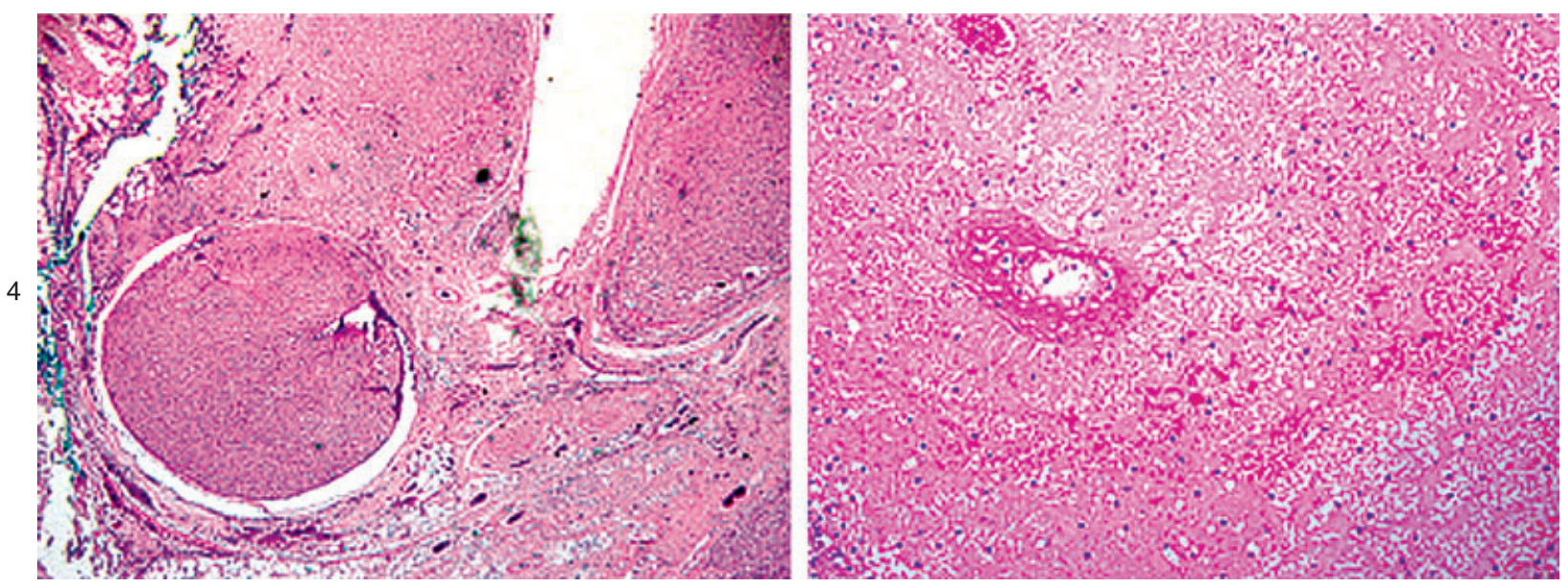

Figure 2. (Continued).

Table 1. Standard invasion criteria in follicular thyroid carcinomas (FTC)

\begin{tabular}{|c|c|c|c|}
\hline & $\begin{array}{l}\text { Minimally } \\
\text { invasive } \\
\text { FTC, no. (\%) }\end{array}$ & $\begin{array}{l}\text { Widely } \\
\text { invasive } \\
\text { FTC, no. (\%) }\end{array}$ & $\begin{array}{l}\text { ATC, } \\
\text { no. }(\%)\end{array}$ \\
\hline \multicolumn{4}{|l|}{ Capsular invasion } \\
\hline Multifocal & $14(50)$ & - & - \\
\hline Unifocal & $14(50)$ & - & - \\
\hline \multicolumn{4}{|l|}{ Vascular invasion } \\
\hline Capsular & $10(36)$ & - & - \\
\hline Extraglandular & $0(0)$ & $6(13)$ & $14(52)$ \\
\hline Intraglandular & $14(50)$ & $20(42)$ & $27(100)$ \\
\hline Capillaries & $18(64)$ & $12(25)$ & $27(100)$ \\
\hline Venules & $4(14)$ & $20(42)$ & $14(52)$ \\
\hline $\begin{array}{l}\text { Lymph node } \\
\text { metastasis }\end{array}$ & $1(3)$ & $5(10)$ & $0(0)$ \\
\hline
\end{tabular}

This vascular invasion pattern was significantly different comparing all carcinomas $(P<0.0001)$, anaplastic thyroid carcinoma (ATC) versus widely invasive FTC $(P=0.0014)$ and widely versus minimally invasive FTC $(P=0.0003)$. The type of involved blood vessels revealed statistically significant differences for the distinction widely versus minimally invasive FTC $(P=0.0206)$. Lymph node metastases were present in FTC revealing oncocytic differentiation or insular graowth pattern.

2 Presence of necrosis, extension and blood vessel involvement.

3 The two predominant tumour growth patterns were recorded and scored 1 (macro-microfollicular), 2 (tra-
Table 2. Growth patterns in follicular thyroid proliferative lesions

\begin{tabular}{lrrrrrr}
\hline & \multicolumn{5}{c}{$\begin{array}{c}\text { Minimally } \\
\text { invasive }\end{array}$} & $\begin{array}{l}\text { Widely } \\
\text { invasive }\end{array}$ \\
& FTHN FTA FTC & FTC & ATC \\
\hline $\begin{array}{l}\text { Primary growth pattern } \\
1 \text { Macro-microfollicular }\end{array}$ & 39 & 43 & 22 & 18 & 0 \\
\hline 2 Trabecular-nested & 0 & 0 & 6 & 16 & 0 \\
\hline 3 Solid-insular & 0 & 0 & 0 & 18 & 0 \\
\hline $\begin{array}{l}4 \text { Solid-pleomorphic/ } \\
\text { vasculonecrotic }\end{array}$ & 0 & 0 & 0 & 0 & 27 \\
\hline $\begin{array}{l}\text { Secondary growth pattern } \\
1 \text { Macro-microfollicular }\end{array}$ & 34 & 35 & 16 & 26 & 4 \\
\hline \begin{tabular}{l}
2 Trabecular-nested \\
\hline Solid-insular
\end{tabular} & 5 & 8 & 12 & 8 & 2 \\
\hline $\begin{array}{l}\text { 4 Solid-pleomorphic/ } \\
\text { vasculonecrotic }\end{array}$ & 0 & 0 & 0 & 0 & 14 & 2 \\
\hline
\end{tabular}

FTHN, Follicular thyroid hyperplastic nodule; FTA, follicular thyroid adenoma; FTC, follicular thyroid carcinoma; ATC, anaplastic thyroid carcinoma.

becular-nested), 3 (solid-insular) or 4 (solid-pleomorphic/vasculo-necrotic) (Figure 2).

4 Tissue reaction, either fibroblastic (homogeneous hyaline) or myxoid (basophilic loose) and its extension.

5 Inflammation type (neutrophilic/lymphocytic/histiocytic) and grade (mild/severe), separately considered in both tumour and surrounding gland.

6 Tumour capsule invasion, defined by tumour cell infiltration through the capsule. 
754 S Arif et al.

Table 3. Histological features of follicular thyroid neoplasms

\begin{tabular}{|c|c|c|c|c|c|c|c|}
\hline & FTA & MI-FTC & WI-FTC & ATC & $\begin{array}{l}\text { FTA versus } \\
\text { MI-FTC }\end{array}$ & $\begin{array}{l}\text { MI-FTC versus } \\
\text { WI-FTC }\end{array}$ & $\begin{array}{l}\text { WI-FTC } \\
\text { versus ATC }\end{array}$ \\
\hline Anisokaryosis & & & & & NS & 0.00241 & 0.00625 \\
\hline$\leq 3 / 1$ & 35 & 22 & 16 & 0 & & & \\
\hline$>3 / 1$ & 8 & 6 & 32 & 27 & & & \\
\hline Chromatin & & & & & NS* & 0.00504 & 0.00022 \\
\hline Regular & 43 & 22 & 15 & 0 & & & \\
\hline Granular & 0 & 4 & 13 & 2 & & & \\
\hline Heterochromatic & 0 & 2 & 20 & 25 & & & \\
\hline Nucleolus & & & & & 0.01752 & NS & 0.04379 \\
\hline Inconspicuous & 4 & 12 & 26 & 25 & & & \\
\hline Conspicuous & 39 & 16 & 22 & 2 & & & \\
\hline Nuclear pleomorphism & & & & & NS* & 0.01237 & 0.00030 \\
\hline Slight & 43 & 24 & 30 & 0 & & & \\
\hline Marked & 0 & 4 & 18 & 27 & & & \\
\hline Nuclear-cytoplasmic ratio & & & & & 0.04912 & 0.02083 & 0.01507 \\
\hline Normal & 39 & 18 & 16 & 0 & & & \\
\hline Increased & 4 & 10 & 32 & 27 & & & \\
\hline Nuclear grade, high grade & & & & & NS & NS & $<0.00001$ \\
\hline$<5$ & 43 & 28 & 46 & 0 & & & \\
\hline$\geq 5$ & 0 & 0 & 2 & 27 & & & \\
\hline Nuclear grade, low grade & & & & & 0.00157 & 0.00122 & NS \\
\hline$\leq 3$ & 35 & 16 & 0 & 0 & & & \\
\hline$>3$ & 8 & 12 & 48 & 27 & & & \\
\hline Necrosis & & & & & NS & 0.00333 & 0.00106 \\
\hline None & 23 & 18 & 8 & 2 & & & \\
\hline Apoptosis & 20 & 6 & 32 & 10 & & & \\
\hline Oncosis & 0 & 4 & 8 & 15 & & & \\
\hline Stromal reaction & & & & & NS & $<0.00001$ & 0.00583 \\
\hline None & 8 & 6 & 6 & 4 & & & \\
\hline Myxoid & 35 & 20 & 0 & 0 & & & \\
\hline Broad fibrous bands & 0 & 2 & 42 & 23 & & & \\
\hline Myxoid stroma and apoptosis & & & & & 0.01499 & NS & NS \\
\hline Absent & 23 & 26 & 45 & 26 & & & \\
\hline Present & 20 & 2 & 3 & 1 & & & \\
\hline Inflammation & & & & & NS & NS & NS \\
\hline Absent & 41 & 24 & 42 & 25 & & & \\
\hline Present & 2 & 4 & 6 & 2 & & & \\
\hline
\end{tabular}


Table 3. (Continued)

\begin{tabular}{|c|c|c|c|c|c|c|c|}
\hline & FTA & MI-FTC & WI-FTC & ATC & $\begin{array}{l}\text { FTA versus } \\
\text { MI-FTC }\end{array}$ & $\begin{array}{l}\text { MI-FTC versus } \\
\text { WI-FTC }\end{array}$ & $\begin{array}{l}\text { WI-FTC } \\
\text { versus ATC }\end{array}$ \\
\hline $\begin{array}{l}\text { Global pattern score } \\
<3\end{array}$ & 35 & 18 & 6 & 0 & 0.01029 & 0.00071 & $<0.00001$ \\
\hline $3-5$ & 8 & 10 & 40 & 0 & & & \\
\hline$\geq 5$ & 0 & 0 & 2 & 27 & & & \\
\hline
\end{tabular}

FTA, Follicular thyroid adenoma; MI-FTC, minimally invasive follicular thyroid carcinoma; WI-FTC, widely invasive follicular thyroid carcinoma; ATC, anaplastic thyroid carcinoma.

7 Vascular invasion (intravascular presence of atypical tumour cells adherent to the wall of endothelialized lumens located at the tumour periphery), type of vessels involved (with or without smooth muscle) and their location (capsular/extracapsular).

8 Perineural invasion (presence of atypical tumour cells surrounding nerve fibres).

9 Cytoplasmic features included staining (eosinophilic, basophilic and clear), appearance (homogeneous, foamy and granular) and the presence of sharp eosinophilic globules. The presence of cytoplasmic pigment (lipofuchsin/melanin) and special features (oncocytic differentiation, sarcomatoid features) were recorded.

10 Nuclear features were independently analysed as reported, ${ }^{11,12}$ including anisokaryosis $(\geq 3: 1)$, pleomorphism (in $>50 \%$ cells), chromatin distribution and presence of prominent nucleolus $/ \mathrm{i}$ in $>50 \%$ of proliferating cells.

11 N/C (nuclear-cytoplasmic) ratio (low/high) compared with that of follicular cells in the surrounding gland.

12 Presence of bi- or multinucleated cells and nuclear pseudoinclusions.

PROLIFERATION ASSESSMENT BY Ki-67

IMMUNOEXPRESSION

The sections were mounted on positively charged slides (Superfrost Plus; Fisher Scientific, Fair Lawn, $\mathrm{NJ}$, USA), baked at $60^{\circ} \mathrm{C}$ for $2 \mathrm{~h}$ and processed as described previously. ${ }^{6,7,13}$ After routine dewaxing and rehydration, endogenous peroxidase quenching and antigen heat retrieval, the slides were transferred to a moist chamber. Non-specific binding was blocked with polyclonal horse serum and sections incubated with MIB-1 monoclonal primary antibody (Dako, Carpinteria, CA, USA; $4 \mu \mathrm{g} / \mathrm{ml}$, overnight, $4^{\circ} \mathrm{C}$ ). Then sections were serially incubated with biotinylated antimouse antibody and peroxidase-labelled

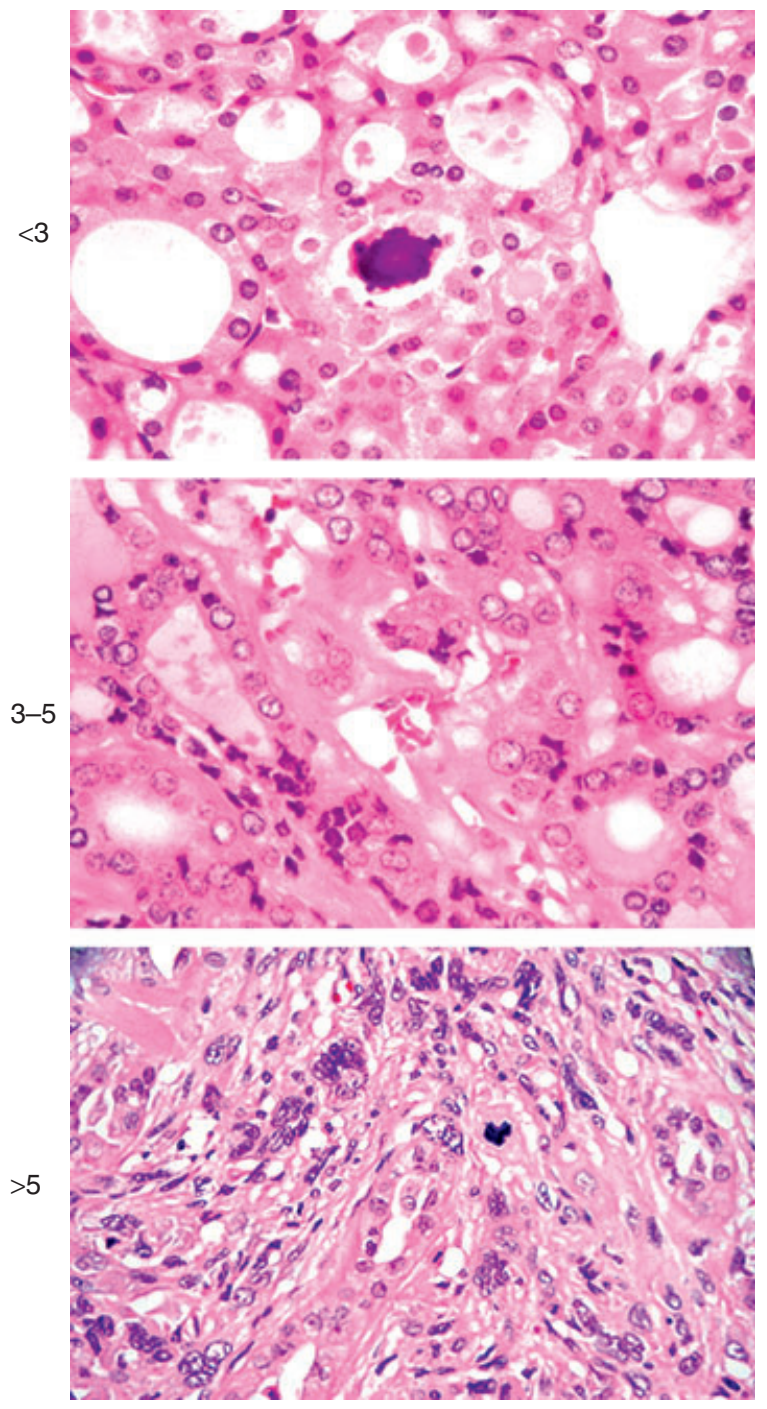

Figure 3. Using the most specific features for malignancy diagnosis a nuclear grade was derived (hyperchromatism + pleomorphism + $1 / 2$ anisokaryosis $+1 / 2$ high nuclear-cytoplasmic ratio), scoring each variable 2 if present and 1 if absent. This nuclear grade was demonstrated to be useful for the distinction of anaplastic thyroid carcinoma versus widely invasive follicular thyroid carcinoma (threshold 5) and to differentiate non-anaplastic follicular lesions (threshold 3) (Table 2). 

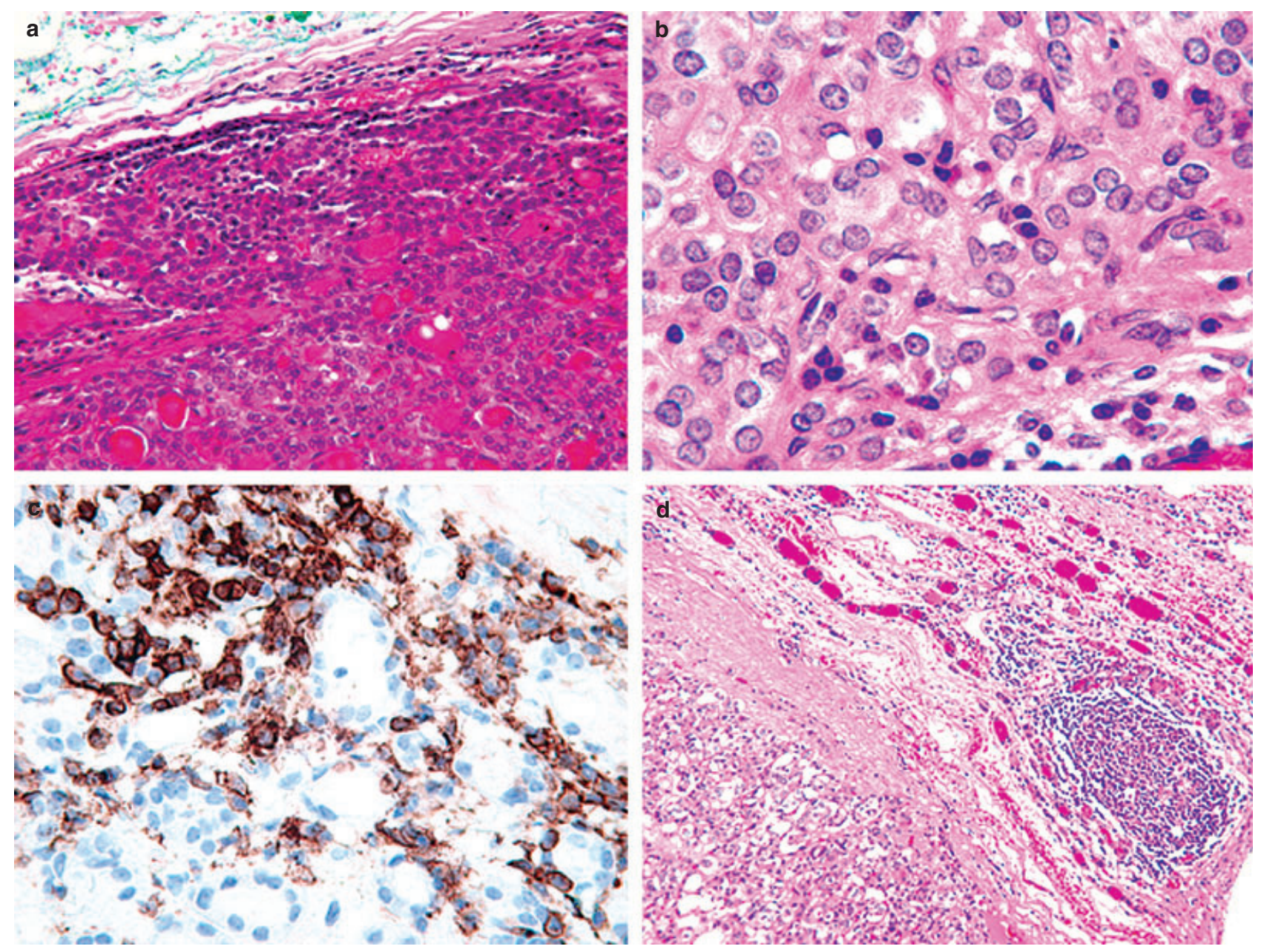

Figure 4. Inflammatory infiltrate in follicular thyroid proliferative lesions. Interstitial lymphocytes were more frequently observed in follicular thyroid hyperplastic nodules (a,b) and revealed a B-cell phenotype (CD20+, c, ABC-peroxidase) than in follicular thyroid adenoma (d, H\&E), where they were present in the peritumoral parenchyma.

avidin-biotin complex. The reaction was developed under microscopic control, using 3,3'-diaminobenzidine tetrahydrochloride with $0.3 \% \mathrm{H}_{2} \mathrm{O}_{2}$ as chromogen (Sigma Co., St Louis, MO, USA) and the sections counterstained with haematoxylin. Both positive (reactive lymph node) and negative (omitting the primary antibody) controls were run simultaneously.

APOPTOSIS DETECTION BY IN SITU END LABELLING

Apoptosis DNA fragmentation was detected by in situ end labelling (ISEL). ${ }^{6,7,13,14}$ After routine dewaxing and hydration, the sections were incubated in $2 \times$ standard saline citrate $\left(20 \mathrm{~min}\right.$ at $\left.80^{\circ} \mathrm{C}\right)$ and digested with pronase ( $500 \mu \mathrm{g} / \mathrm{ml}, 25 \mathrm{~min}$, room temperature) in a moist chamber.

DNA fragments were labelled on 5'-protruding termini by incubating the sections with the Klenow fragment of Escherichia coli DNA polymerase I $(20 \mathrm{U} / \mathrm{ml}$ in $50 \mathrm{mmol} / \mathrm{l}$ Tris-HCl, pH 7.5, $10 \mathrm{mmol} / \mathrm{l}$ $\mathrm{MgCl}_{2}, 1 \mathrm{mmol} / \mathrm{l}$ dithiothreitol, $250 \mu \mathrm{g} / \mathrm{ml}$ bovine serum albumin, $5 \mu \mathrm{M}$ of each 2'-deoxyadenosine 5'triphosphate (dATP), 2'-deoxycytidine 5'-triphosphate (dCTP), 2'-deoxyguanosine 5'-triphosphate (dGTP), as well as $3.25 \mu \mathrm{mol} / \mathrm{l} 2$ '-deoxythymidine 5'-triphosphate (dTTP) and $1.75 \mu \mathrm{mol} / \mathrm{l}$ 11-digoxigenin-2'-deoxyuridine 5'-triphosphate $(d U T P)$, at $37^{\circ} \mathrm{C}$ in a moist chamber. The incorporated digoxigenin-deoxyuridinmonophosphates (digoxigenin-dUMPs) were immunoenzymatically detected by using antidigoxigenin $\mathrm{Fab}$ fragments labelled with alkaline phosphatase $(7.5 \mathrm{U} / \mathrm{ml}$, in $100 \mathrm{mmol} / \mathrm{l}$ Tris-HCl, pH 7.6, $150 \mathrm{mmol} / \mathrm{l} \mathrm{NaCl}$, $1 \%$ bovine serum albumin) for $4 \mathrm{~h}$ at room temperature. The reactions were developed with the mixture nitroblue tetrazolium-X phosphate in $100 \mathrm{mmol} / \mathrm{l}$ Tris- $\mathrm{HCl}$ (pH 9.5) and $100 \mathrm{mmol} / \mathrm{l} \mathrm{NaCl}, 50 \mathrm{mmol} / \mathrm{l} \mathrm{MgCl}_{2}$ 


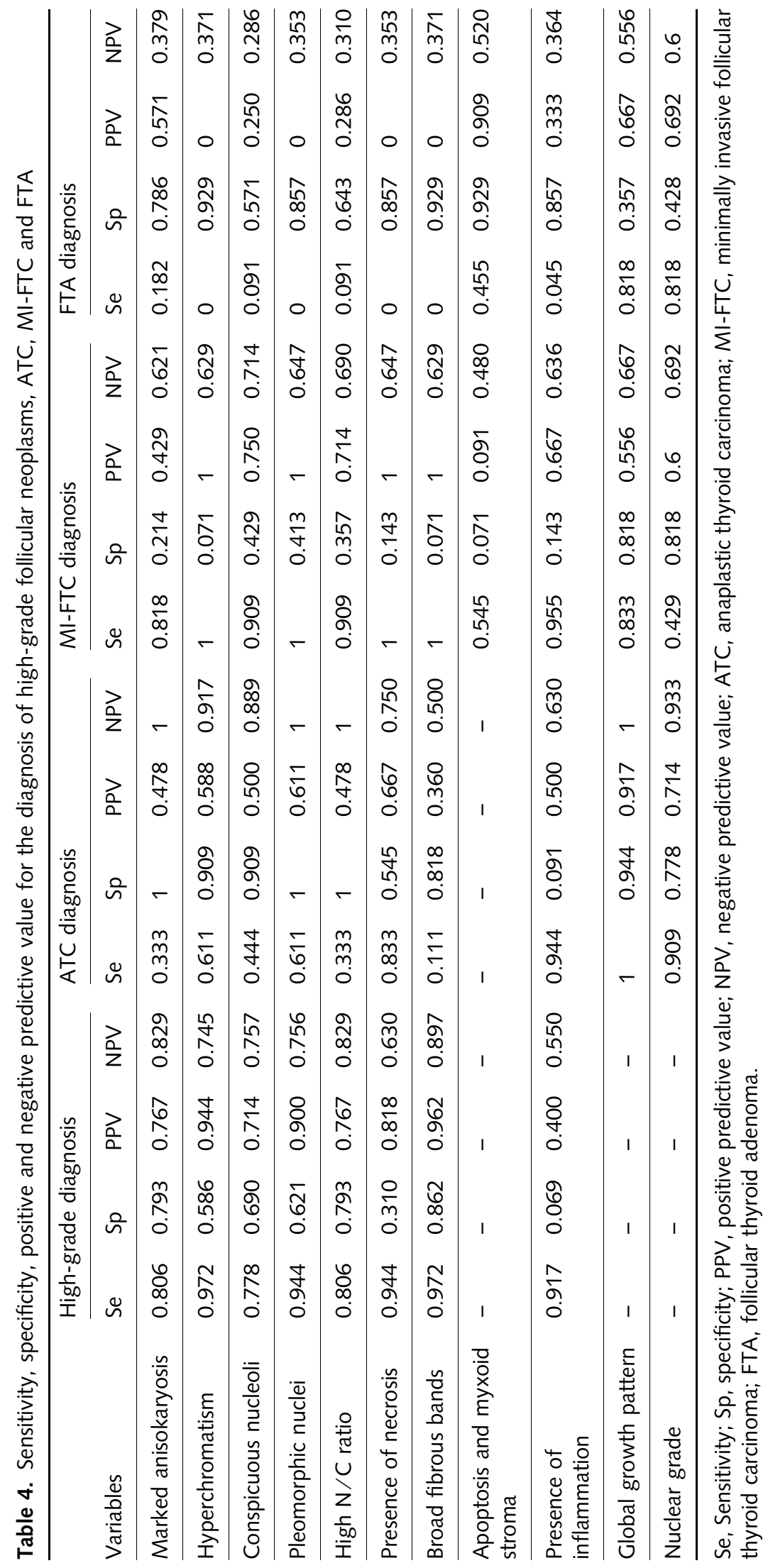


under microscopic control. Appropriate controls were simultaneously run, including positive (reactive lymph node), negative (same conditions omitting DNA polymerase I), and enzymatic (DNase I prelabelling digestion). The enzymatic controls were used to establish reliably the positivity threshold in each sample.

\section{QUANTIFICATION OF POSITIVE NUCLEI AND}

STATISTICAL ANALYSIS

At least 50 high-power fields $\left(7.6 \mathrm{~mm}^{2}\right)$ were screened in each pathological group, beginning in the most cellular area. The number of positive nuclei was expressed per 1000 tumour cells and the average and standard deviation (SD) calculated in each pathological condition, topographical compartment and patient as described. ${ }^{5-7,13,14}$ The positivity threshold was experimentally established from the positive control in each staining batch. Only nuclei with staining features similar to those of their corresponding positive control were considered positive for any marker.

Results were compared by diagnostic groups using Pearson's $\chi^{2}$ test (with Yates' correction if necessary) and Fisher's exact test for qualitative variables and Student's $t$-test (if normal distribution) and analysis of variance (ANOVA, if non-parametric distribution) for quantitative variables. Normal distribution was previously tested by the Kolmogorov-Smirnoff test. The results were considered statistically significant if $P<0.05$ in two-tailed distributions. Specificity, sensitivity and predictive values for both positive and negative tests were calculated for: (i) high-grade neoplasms (ATC and WI-FTC) versus low-grade neoplasms (MI-FTC and FTA); (ii) ATC versus WI- FTC; and (iii) MI-FTC versus FTA.

\section{Results}

At the last review, 24 patients with MI-FTC (86\%) and 10 patients with WI-FTC (21\%) remained disease free; the survival for patients with ATC was $20.6 \pm$
11.5 months. No patient with a benign diagnosis died of disease. The median follow-up of 30 survivors was 233.5 months; 64 patients died of carcinoma (one minimally invasive carcinoma, 36 widely invasive carcinomas and all cases of ATC).

\section{HISTOLOGICAL EVALUATION, SENSITIVITY AND SPECIFICITY}

The record of invasive features in this FTC series appears in Table 1. Primary and secondary growth patterns were macro-microfollicular for FTHN, FTA, MI-FTC and WI-FTC, and solid-vasculonecrotic for ATC (Table 2); the global pattern score demonstrated statistically significant differences when categorized in three groups $(<3,3-5, \geq 5)$ (Table 3). The nuclear features showed progressive abnormalities, which helped to distinguish diagnostic groups even after assessing them independently (Table 3, Figure 3). Oncocytic differentiation was observed in 10 FTC (six minimally invasive and four widely invasive) and six FTA; no hyalinizing trabecular neoplasms were identified.

Lymphocytic inflammation (Figure 4) was observed in 19 cases of adenomatous FTHN (49\%), within the peritumoral parenchyma in 64 cases $(44 \%)$ and in the neoplastic interstitium in six cases $(4 \%)$; these results demonstrate statistically significant differences between FTHN and neoplasms $(P<0.0001)$. Adenomatous FTNH, as defined in the selection criteria, was distinguished from FTA by the presence of inflammation and the absence of myxo-oedematous stromal changes (focally present in only one FTNH).

Most histological features revealed statistically significant differences for the benign-malignant distinction (Table 3), especially when high-grade FTCs were included. High-grade FTCs were characterized by prominent anisokaryosis, gross heterochromatin, conspicuous nucleoli, marked nuclear pleomorphism and high N/C ratio (Table 3). Both a fibroblastic tissue reaction and necrosis were mainly observed in highgrade FTC, necrosis involving simultaneously tumour

Figure 5. To generate this algorithm, histological variables were hierarchically introduced (specificity first) and all diagnostic categories were required to be defined by at least three cytoarchitectural features. The numbers close to each variable represent the probability of not finding it in the corresponding diagnostic group; the mathematical value represents the predicted probability of not being in a given diagnostic group when all the features are met. The final diagnostic accuracy is provided in the final line.The algorithm has two main arms, first for tumours without broad fibrous bands-we would expect most of these to be follicular thyroid adenomas and minimally invasive follicular thyroid carcinomas (FTCs). Coexistent myxoid stroma and apoptosis were highly sensitive for follicular adenoma. In the low-grade group, prominent nucleoli and increased nuclear-cytoplasmic ratio were the most specific variables in distinguishing between minimally invasive carcinoma and adenoma.To diagnose high-grade FTC, the most specific feature is the presence of broad fibrous bands, while necrosis is the most specific variable in the distinction of widely invasive FTC vs. anaplastic thyroid carcinoma. This was confluent necrosis, involving both tumour cells and blood vessels. Nuclear pleomorphism and hyperchromatism were less specific but still relevant in distinguishing between widely invasive and anaplastic: the diagnosis of anaplastic carcinoma should not be made in its absence, as defined in this study by irregularity of the nuclear outline. 

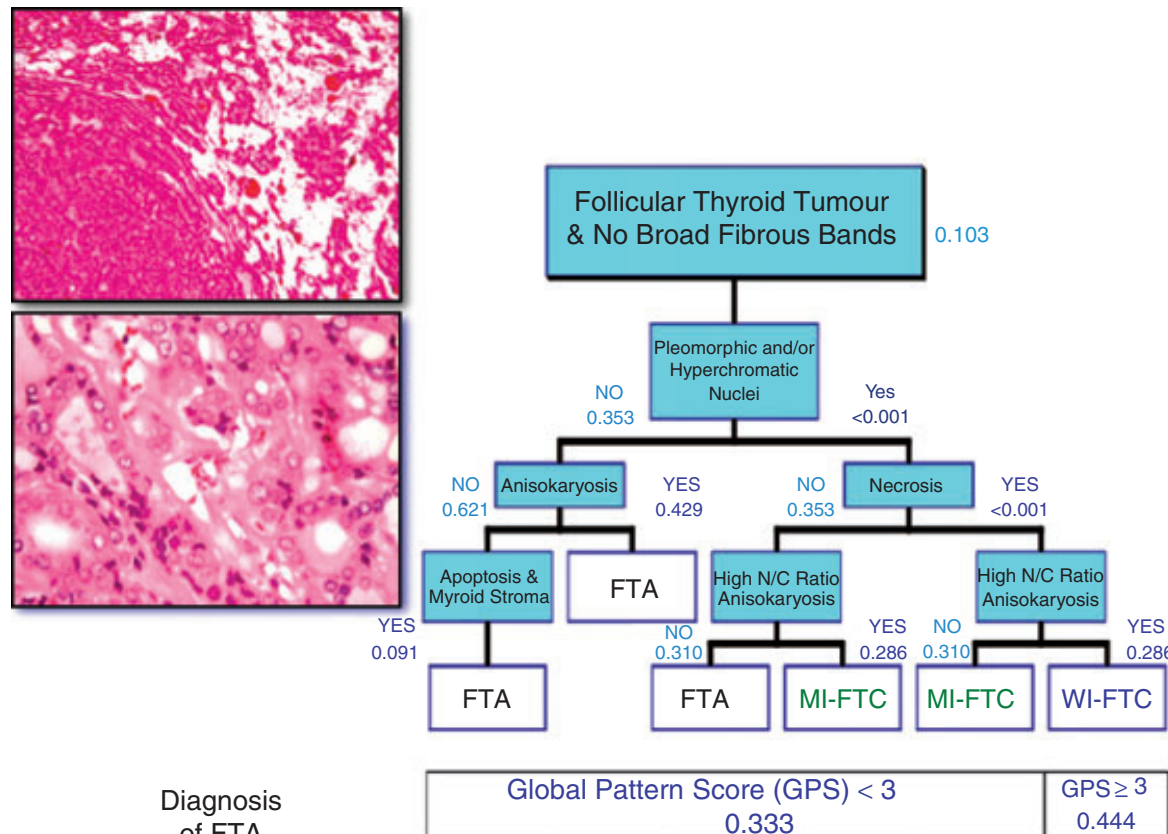

of FTA

\begin{tabular}{|c|c|c|c|c|c|}
\hline \multicolumn{5}{|c|}{ Global Pattern Score (GPS) $<3$} & GPS $\geq 3$ \\
0.444 \\
\hline FTA & FTA & FTA & MI-FTC & MI-FTC & WI-FTC \\
0.001 & 0.005 & $3.810^{-6}$ & $3.510^{-6}$ & $1.110^{-6}$ & $1.310^{-6}$ \\
\hline Accuracy & Accuracy & \multicolumn{3}{|c|}{ Diagnosis correctly predicted with accuracy } \\
$99.9 \%$ & $99.5 \%$ & \multicolumn{4}{|c}{$>99.9 \%$} \\
\hline
\end{tabular}
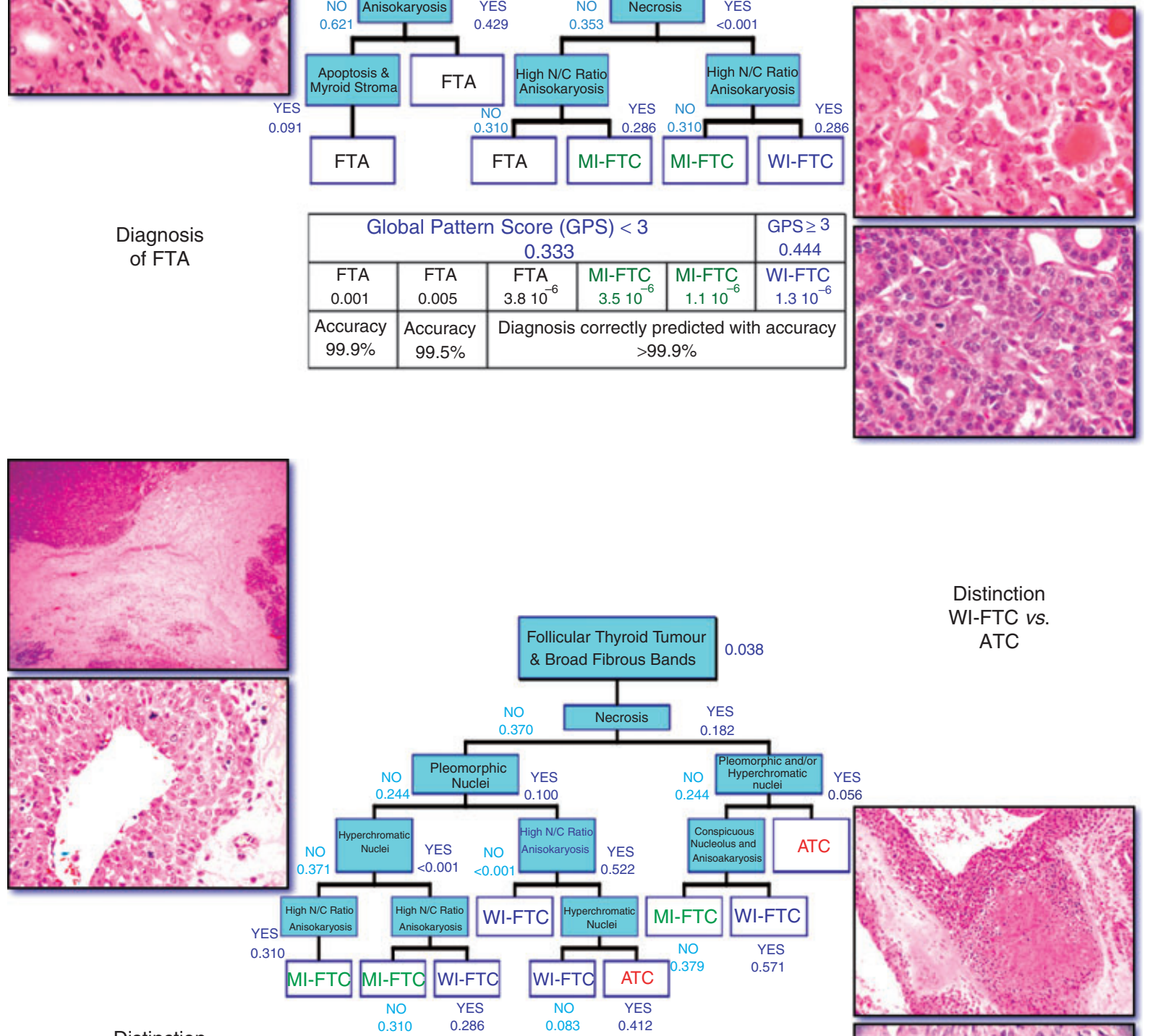

Distinction

MI-FTC vs.

FTC

\begin{tabular}{|c|c|c|c|c|c|c|c|c|}
\hline $\begin{array}{r}\text { GPS } \\
0.3\end{array}$ & $\begin{array}{l}5<3 \\
333\end{array}$ & & $\begin{array}{c}\text { GPS } \geq 3 \\
0.444\end{array}$ & & $\begin{array}{c}G P S \geq 5 \\
0.083\end{array}$ & $\begin{array}{c}\text { GPS }<3 \\
0.333\end{array}$ & $\begin{array}{c}\text { GPS } \geq 3 \\
0.444 \\
\end{array}$ & $\begin{array}{c}\text { GPS } \geq 5 \\
0.083 \\
\end{array}$ \\
\hline $\begin{array}{r}\text { MI-FTC } \\
1.310^{-4}\end{array}$ & \begin{tabular}{|c|}
$\mathrm{Ml}-\mathrm{FTC}$ \\
$3.510^{-7}$
\end{tabular} & $\begin{array}{l}\text { WI-FTC } \\
4.410^{-7}\end{array}$ & \begin{tabular}{|c|} 
WI-FTC \\
$6.210^{-7}$
\end{tabular} & $\begin{array}{l}\text { WI-FTC } \\
2.710^{-5}\end{array}$ & $\begin{array}{l}\text { ATC } \\
2.510^{-5}\end{array}$ & $\begin{array}{c}\text { MI-FTC } \\
3.310^{-4}\end{array}$ & $\begin{array}{c}\text { WI-FTC } \\
4.410^{-4}\end{array}$ & $\begin{array}{l}\text { ATC } \\
3.210^{-5}\end{array}$ \\
\hline
\end{tabular}

Diagnosis correctly predicted with accuracy $>99.9 \%$

Distinction

WI-FTC vs.

ATC
Distinction

MI-FTC 
cells and blood vessels in ATC. Myxoid stromal reaction was observed only in FTA and MI-FTC, coexisting with apoptotic follicular cells in FTA (Table 3). Interstitial lymphocytes were absent in 140/146 (96\%) neoplasms, regardless of histological subtype, and no statistically significant differences were observed between neoplasms.

Minimally invasive carcinomas were distinguished from adenomas by conspicuous nucleoli $(P=0.0175)$ and increased $\mathrm{N} / \mathrm{C}$ ratio $(P=0.0491)$, whereas the coexistence of apoptosis and myxoid stroma was the only positive finding characterizing FTA $(P=0.0150)$. The most specific variables of high-grade carcinoma were the presence of coagulative necrosis, hyperchromatic nuclei and nuclear pleomorphism.

Sensitivity and specificity results (Table 4) were readily applicable in a step-wise cytoarchitectural diagnostic system for follicular thyroid neoplasms (Figure 5). Using the most specific features for the diagnosis of malignancy, nuclear grade was also determined (Figure 3, Table 3).

\section{CELL KINETICS BY TOPOGRAPHICAL COMPARTMENTS}

Variable levels of proliferation and apoptosis markers were observed in peripheral (PC) and internal compartments (IC) (Table 5, Figure 6), with statistically significant results for Ki67/ISEL in the FTA and welldifferentiated WI-FTC and when all the benign (ICs) or malignant (PCs) lesions were grouped together. Topographically, the Ki67/ISEL indices revealed a predominant kinetic advantage in the ICs of benign lesions and in the PCs of malignant lesions (Table 5). These results were due to the statistically significant decrease in ISEL indices in the IC in adenomas $(5.3 \pm 7.8 \%$ versus $1.3 \pm 2.4 \% ; P=0.0213)$ and in the PCs in carcinomas $(1.4 \pm 1.7 \%$ versus $2.3 \pm 5.5 \% ; P=0.0474)$.

Benign lesions (FTHN and FTA) and low-grade malignancies (MI-FTC) showed higher rates of apoptosis in PCs compared with ICs, while high-grade malignancies (WI-FTC, ATC) revealed the inverse relationship (Table 5).

\section{Discussion}

The step-wise cytoarchitectural system developed here helps to classify follicular thyroid lesions, improves the classification reliability and correlates with the topographical kinetic features. Prominent nuclear alterations, necrosis and a fibroblastic tissue reaction characterize high-grade FTC, while a myxo-oedematous stromal reaction and apoptotic follicular cells correlate with low-grade follicular neoplasms. A systematic evaluation of growth patterns significantly improves accuracy. The kinetic profile provides a basis for separating benign from malignant lesions and an explanation as to why benign lesions are well circumscribed and encapsulated. A minimal interstitial lymphocytic infiltrate characterizes follicular thyroid neoplasms and helps to distinguish them from hyperplastic nodules.

For the first time, this study provides a detailed evaluation of cytoarchitectural features for grading/ classifying follicular thyroid neoplasms and the corresponding diagnostic probability resulting from such a step-wise evaluation system (Figure 5). Currently, the

Table 5. Ki67 and ISEL indices by topographical compartments in follicular thyroid proliferative lesions

\begin{tabular}{|c|c|c|c|c|c|c|c|c|}
\hline & \multicolumn{4}{|c|}{ Peripheral compartment } & \multicolumn{4}{|c|}{ Internal compartment } \\
\hline & $\begin{array}{l}\mathrm{Ki} 67(\%) \\
\mathrm{Av} \pm \mathrm{SD}\end{array}$ & $\begin{array}{l}\text { ISEL (\%) } \\
A V \pm S D\end{array}$ & Significance & $\begin{array}{l}\text { Ki67/ISEL } \\
\text { index (\%) }\end{array}$ & $\begin{array}{l}\mathrm{Ki} 67(\%) \\
A v \pm S D\end{array}$ & $\begin{array}{l}\text { ISEL }(\%) \\
A v \pm S D\end{array}$ & Significance & $\begin{array}{l}\text { Ki67/ISEL } \\
\text { index (\%) }\end{array}$ \\
\hline Benign & $5.1 \pm 7.2$ & $4.7 \pm 3.4$ & NS & $1.1 \pm 1.5$ & $6.3 \pm 6.6$ & $1.8 \pm 4.1$ & $P=0.0015$ & $3.5 \pm 3.7$ \\
\hline FTHN & $5.5 \pm 4.4$ & $4.6 \pm 5.9$ & NS & $1.2 \pm 0.9$ & $8.8 \pm 11.9$ & $3.1 \pm 7$ & NS & $2.8 \pm 3.8$ \\
\hline FTA & $4.9 \pm 3.5$ & $5.3 \pm 7.8$ & $P=0.046$ & $0.9 \pm 0.7$ & $6.8 \pm 7.5$ & $1.3 \pm 2.4$ & $P=0.013$ & $5.2 \pm 5.8$ \\
\hline Malignant & $12.0 \pm 50.6$ & $3.8 \pm 7.4$ & $P=0.019$ & $3.2 \pm 13.3$ & $8.6 \pm 1.5$ & $2.4 \pm 6.1$ & NS & $3.6 \pm 0.6$ \\
\hline MI-FTC & $8.6 \pm 13$ & $5.8 \pm 12$ & NS & $1.5 \pm 2.2$ & $2.9 \pm 3$ & $4.3 \pm 10$ & NS & $0.7 \pm 0.7$ \\
\hline WI-FTC & $7.6 \pm 8.8$ & $1.4 \pm 1.7$ & $P=0.003$ & $5.4 \pm 6.3$ & $3.5 \pm 4.8$ & $2.3 \pm 5.5$ & NS & $1.5 \pm 2.1$ \\
\hline ATC & $53 \pm 50$ & $9 \pm 15$ & $P=0.029$ & $5.9 \pm 5.6$ & $36 \pm 32$ & $1 \pm 1$ & NS & $36.0 \pm 32.0$ \\
\hline
\end{tabular}

ISEL, In situ end labelling; FTHN, follicular thyroid hyperplastic nodule; FTA, follicular thyroid adenoma; MI-FTC, minimally invasive follicular thyroid carcinoma; WI-FTC, widely invasive follicular thyroid carcinoma; ATC, anaplastic thyroid carcinoma. 

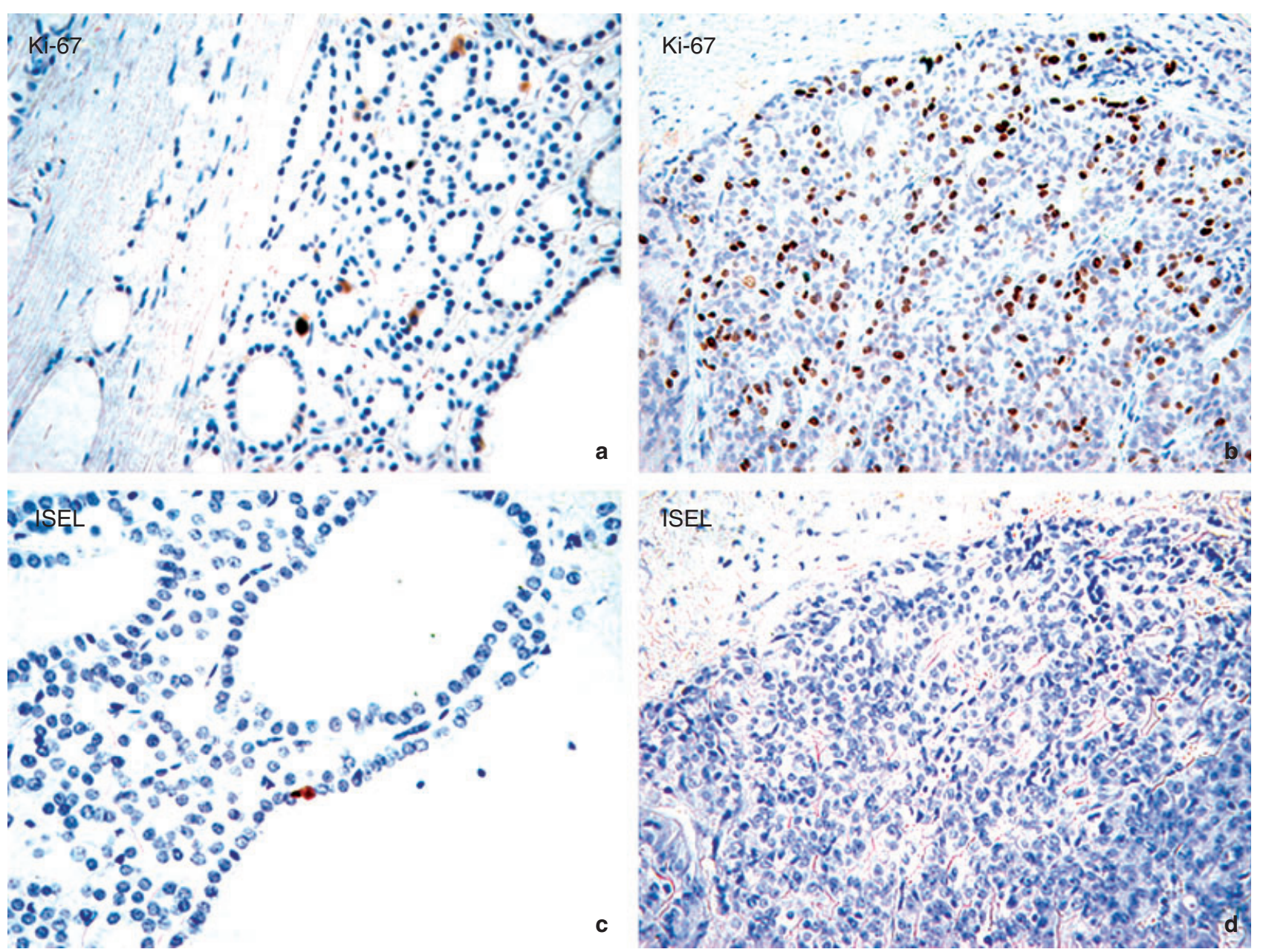

Figure 6. Ki67 and in situ end labelling (ISEL) in benign (a,c) and malignant (b,d) follicular thyroid neoplasms. Both increased proliferation and decreased apoptosis characterize malignancies (right panels), as demonstrated by Ki67 immunohistochemistry and ISEL.

diagnosis of follicular thyroid lesions relies on the pathologist's experience; ${ }^{15}$ in particular, this is true of the assessment of capsular and vascular invasion in encapsulated neoplasms, ${ }^{2}$ with the diagnosis of malignancy being based mainly on the evidence of infiltration and vascular invasion. This has resulted in two prognostic categories: encapsulated (minimally invasive) and non-encapsulated (widely invasive) neoplasms, with different metastatic risk (higher rates for tumours with evidence of vascular invasion than for those with capsular invasion only). ${ }^{16}$ However, accurate diagnosis may also be required when a limited amount of tissue is available; in this situation alternative criteria must be applied, which must still be reliable and precise. ${ }^{17}$ Nuclear features have been previously evaluated in cytological material, but are significant only with the use of computer-assisted karyometric or densitometric analyses, ${ }^{18-20}$ or measuring the nucleolar area. ${ }^{21}$ Such techniques are not always available for routine diagnosis.
Our step-wise application of diagnostic criteria based on their specificity gives an overall diagnostic accuracy 99.9\% when tested against the current diagnostic criteria and is mainly based on tumour invasiveness, the presence of broad fibrous bands, necrosis, tumour growth pattern and nuclear grading (hyperchromatism, pleomorphism, anisokaryosis and $\mathrm{N} / \mathrm{C}$ ratio). Broad fibrous bands and necrosis are key variables in the assessment of malignancy in parathyroid and adrenocortical neoplasms, ${ }^{22-25}$ but they have not been emphasized for high-grade FTC diagnosis (including ATC). They reflect invasive capacity and high cellular turnover, which result in specific growth patterns, solid-pleomorphic and vasculo-necrotic, the latter with necrosis involving tumour cells and blood vessels simultaneously, as reported in glioblastoma multiforme. ${ }^{26,27}$ Pattern analysis in neoplasms should be considered equivalent to grading and has been successfully used in heterogeneous neoplasms such as 
prostatic adenocarcinoma, ${ }^{28}$ but has not been extensively applied to other neoplasms.

Nuclear features (prominent nucleoli and high N/C ratio for low-grade carcinomas and hyperchromatism and nuclear pleomorphism for high-grade carcinomas) directly reflect neoplastic kinetic features. ${ }^{29}$ The kinetic profile provides a basis to separate benign from malignant lesions and an explanation as to why benign lesions are well circumscribed and encapsulated. Inverse proliferation/apoptosis correlations characterized benign and malignant tumours, a kinetic advantage predominating in ICs of benign lesions and in PCs of malignant lesions. Benign lesions demonstrated an inverse proliferation-apoptosis correlation (increasing apoptosis and decreasing proliferation) in the PCs and a direct correlation in ICs. The opposite profile was observed in carcinomas, confirming the kinetic equivalency between superficial/internal and deep/peripheral compartments of neoplasms from luminal and solid organs. $^{5-7}$ Cell kinetics (proliferation and apoptosis) represents the basic mechanism leading to clonal expansion and tumour growth ${ }^{29-34}$ and contributes to the theory of tumour cell topographical segregation..$^{5-7,13,14}$ High proliferation rates in ICs of FTA and FTHN support this theory. For fibrosis to occur, cells need to be in a quiescent/stable phase to create little pressure, but the excess proliferation would increase the pressure towards the tumour periphery. This high pushing force fragments the fragile fibres, interfering with capsule formation. This may explain why highgrade tumours show no capsule, while the lower proliferation rates at the periphery of FTA would result in a reduced pushing force encouraging capsule formation. High rates of apoptosis induce fibrosis and release factors that aid capsule formation. Both these features therefore play a role in the formation and integrity of the capsule.

High-grade neoplasms show high apoptotic indices, which should be the result of the accumulation of genetic mutations reaching lethal levels for the cell. ${ }^{31-33}$ Follicular tumour progression correlates with up-regulation of proliferation and relative down-regulation of apoptosis in PCs, suggesting survival and replication of genetically damaged cells leading to the accumulation of genetic mutations: ${ }^{5-7,13,14}$ high cell proliferation would transfer mutations to daughter cells, while reduced apoptosis would allow cells carrying mutations to complete the cell cycle.

Adenomatous FTHN essentially showed FTA cytoarchitectural features, but revealed a significant increase in interstitial lymphocytes. Tumour-infiltrating lymphocytes were present in a small proportion of neoplasms, suggesting a down-regulated inflammatory reaction that correlates with the relatively poor HLADR expression in FTC, in contrast to papillary carcinoma, in which HLA-DR expression co-exists with CD45RO, a molecule recognizing memory cells. ${ }^{35,36}$ It is also supported by the down-regulation of proinflammatory molecules in microarray assays. ${ }^{29,37}$ The most useful findings differentiating FTHN from FTA were the presence of interstitial lymphocytes (FTHN) and myxoid changes (FTA).

In conclusion, cytoarchitectural features reliably differentiate high-grade FTC (prominent nuclear alterations, necrosis and fibroblastic tissue reaction) from low-grade follicular neoplasms (myxo-oedematous stromal reaction and apoptotic follicular cells), especially after incorporating growth pattern analysis (scoring the two predominant patterns). A minimal interstitial lymphocytic infiltrate characterizes follicular thyroid neoplasms and helps to distinguish them from FTHN. The kinetic profile provides a basis for separating benign from malignant lesions and an explanation as to why benign lesions are well circumscribed and encapsulated.

\section{References}

1. Derwahl M, Studer H. Hyperplasia versus adenoma in endocrine tissues: are they different? Trends Endocrinol. Metab. 2002; 13; 23-28.

2. Hirokawa M, Carney JA, Goellner JR et al. Observer variation of encapsulated follicular lesions of the thyroid gland. Am. J. Surg. Pathol. 2002; 26; 1508-1514.

3. Lloyd R, DeLellis R, Heitz P, Eng C. Pathology and genetics of tumours of endocrine organs. Geneva: WHO Press 2004.

4. Tallini G, Garcia-Rostan G, Herrero A et al. Downregulation of p27KIP1 and Ki67/Mib1 labeling index supports the classification of thyroid carcinoma into prognostically relevant categories. Am. J. Surg. Pathol. 1999; 23; 678-685.

5. Diaz-Cano SJ, Blanes A, Rubio J, Matilla A, Wolfe HJ. Molecular evolution and intratumor heterogeneity by topographic compartments in muscle-invasive transitional cell carcinoma of the urinary bladder. Lab. Invest. 2000; 80; 279-289.

6. Blanes A, Rubio J, Martinez A, Wolfe HJ, Diaz-Cano SJ. Kinetic profiles by topographic compartments in muscle-invasive transitional cell carcinomas of the bladder: role of TP53 and NF1 genes. Am. J. Clin. Pathol. 2002; 118; 93-100.

7. Blanes A, Sanchez-Carrillo JJ, Diaz-Cano SJ. Topographic molecular profile of pheochromocytomas: role of somatic downregulation of mismatch repair. J. Clin. Endocrinol. Metab. 2006; 91; $1150-1158$.

8. Rosai J, Carcangiu ML, DeLellis RA. Tumors of the thyroid gland. In Rosai J, Sobin L eds. Atlas of tumor pathology, 3rd series. Washington, DC: Armed Forces Institute of Pathology 1991.

9. Lloyd RV, Douglas BR, Young WRJ. Endocrine diseases. Washington, DC: American Registry of Pathology and the Armed Forces Institute of Pathology 2002.

10. de Miguel M, Blanes A, Galera H, Diaz-Cano SJ. Critical reappraisal of pathologic criteria for the diagnosis of adreno- 
cortical proliferative lesions. J. Pathol. 2002; 198 (Suppl.); 50A (Abstract).

11. Pozo L, Camacho F, Rios-Martin JJ, Diaz-Cano SJ. Cell proliferation in skin tumors with ductal differentiation: patterns and diagnostic applications. J. Cutan. Pathol. 2000; 27; 292-297.

12. Pozo L, Naase M, Cerio R, Blanes A, Diaz-Cano SJ. Critical analysis of histologic criteria for grading atypical (dysplastic) melanocytic nevi. Am. J. Clin. Pathol. 2001; 115; 194-204.

13. Diaz-Cano SJ, de Miguel M, Blanes A, Tashjian R, Galera H, Wolfe HJ. Clonality as expression of distinctive cell kinetics patterns in nodular hyperplasias and adenomas of the adrenal cortex. Am. J. Pathol. 2000; 156; 311-319.

14. Diaz-Cano SJ, de Miguel M, Blanes A, Tashjian R, Galera H, Wolfe HJ. Clonal patterns in phaeochromocytomas and MEN-2A adrenal medullary hyperplasias: histological and kinetic correlates. J. Pathol. 2000; 192; 221-228.

15. LiVolsi VA, Baloch ZW. Follicular neoplasms of the thyroid: view, biases, and experiences. Adv. Anat. Pathol. 2004; 11; 279-287.

16. van Heerden JA, Hay ID, Goellner JR et al. Follicular thyroid carcinoma with capsular invasion alone: a nonthreatening malignancy. Surgery 1992; 112; 1130-1136; discussion 1136-1138.

17. Lloyd RV, Erickson LA, Casey MB et al. Observer variation in the diagnosis of follicular variant of papillary thyroid carcinoma. Am. J. Surg. Pathol. 2004; 28; 1336-1340.

18. Galera-Davidson H, Bibbo M, Bartels PH et al. Differential diagnosis between follicular adenoma and follicular carcinoma of the thyroid by marker features. Anal. Quant. Cytol. Histol. 1986; 8; 195-200.

19. Galera-Davidson H, Bibbo M, Bartels PH, Dytch HE, Puls JH, Wied GL. Correlation between automated DNA ploidy measurements of Hürthle-cell tumors and their histopathologic and clinical features. Anal. Quant. Cytol. Histol. 1986; 8; 158-167.

20. Montironi R, Alberti R, Sisti S, Braccischi A, Scarpelli M, Mariuzzi GM. Discrimination between follicular adenoma and follicular carcinoma of the thyroid: preoperative validity of cytometry on aspiration smears. Appl. Pathol. 1989; 7; 367-374.

21. Montironi R, Braccischi A, Scarpelli M, Sisti S, Alberti R. Well differentiated follicular neoplasms of the thyroid: reproducibility and validity of a 'decision tree' classification based on nucleolar and karyometric features. Cytopathology 1992; 3; 209-222.

22. Hough AJ, Hollifield JW, Page DL, Hartmann WH. Prognostic factors in adrenal cortical tumors. A mathematical analysis of clinical and morphologic data. Am. J. Clin. Pathol. 1979; 72; 390-399.
23. van Slooten H, Schaberg A, Smeenk D, Moolenaar AJ. Morphologic characteristics of benign and malignant adrenocortical tumors. Cancer 1985; 55; 766-773.

24. Weiss LM. Comparative histologic study of 43 metastasizing and nonmetastasizing adrenocortical tumors. Am. J. Surg. Pathol. 1984; 8; 163-169.

25. Schantz A, Castleman B. Parathyroid carcinoma. A study of 70 cases. Cancer 1973; 31; 600-605.

26. Alvord EC Jr. Is necrosis helpful in the grading of gliomas? Editorial opinion. J. Neuropathol. Exp. Neurol. 1992; 51; 127132.

27. Barker FG 2nd, Davis RL, Chang SM, Prados MD. Necrosis as a prognostic factor in glioblastoma multiforme. Cancer 1996; 77; 1161-1166.

28. Gleason DF. Histologic grade, clinical stage, and patient age in prostate cancer. NCI Monogr. 1988; 15-18.

29. Diaz-Cano SJ. MAP kinase common pathway in thyroid carcinomas of follicular differentiation. J. Pathol. 2006; 210; 133-134.

30. Diaz-Cano SJ. Adrenal medullary proliferation and clonality. In 87th Annual Meeting of the US and Canadian Academy of Pathology; 28 February to 6 March 1998; Boston, MA, USA. 1998.

31. Diaz-Cano SJ, Blanes A, Wolfe HJ. PCR techniques for clonality assays. Diagn. Mol. Pathol. 2001; 10; 24-33.

32. Diaz-Cano SJ. Designing a molecular analysis of clonality in tumours. J. Pathol. 2000; 191; 343-344.

33. Diaz-Cano SJ. Clonality studies in the analysis of adrenal medullary proliferations: application principles and limitations. Endocr. Pathol. 1998; 9; 301-316.

34. Pomerance M, Quillard J, Chantoux F, Young J, Blondeau JP. High-level expression, activation, and subcellular localization of p38-MAP kinase in thyroid neoplasms. J. Pathol. 2006; 209; 298-306.

35. Lahat N, Sheinfeld M, Sobel E, Kinarty A, Kraiem Z. Divergent effects of cytokines on human leukocyte antigen-DR antigen expression of neoplastic and non-neoplastic human thyroid cells. Cancer 1992; 69; 1799-1807.

36. Lindhorst E, Schumm-Draeger PM, Bojunga J, Usadel KH, Herrmann G. Differences in tumor cell proliferation, HLA DR expression and lymphocytic infiltration in various types of thyroid carcinoma. Exp. Clin. Endocrinol. Diabetes 2002; 110; 27-31.

37. Arif S, Patel J, Blanes A, Diaz-Cano SJ. Gene expression and phenotype in follicular thyroid neoplasms. Lab. Invest. 2004; 84; 321A. 